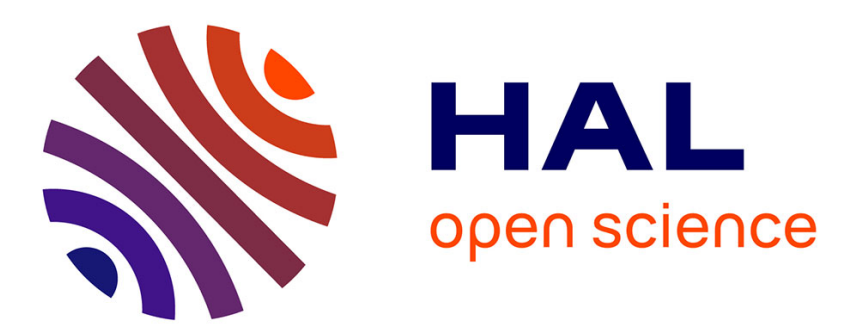

\title{
Comparison of multi-pass and regenerative strategies for energetic high-gain amplifiers based on Yb:CaF2
}

Frédéric Druon, Kévin Genevrier, Patrick Georges, Dimitris N Papadopoulos

\section{To cite this version:}

Frédéric Druon, Kévin Genevrier, Patrick Georges, Dimitris N Papadopoulos. Comparison of multipass and regenerative strategies for energetic high-gain amplifiers based on Yb:CaF2. Optics Letters, 2020, 45, 10.1364/ol.398612 . hal-02991512

\section{HAL Id: hal-02991512 \\ https://hal.science/hal-02991512}

Submitted on 12 Nov 2020

HAL is a multi-disciplinary open access archive for the deposit and dissemination of scientific research documents, whether they are published or not. The documents may come from teaching and research institutions in France or abroad, or from public or private research centers.
L'archive ouverte pluridisciplinaire HAL, est destinée au dépôt et à la diffusion de documents scientifiques de niveau recherche, publiés ou non, émanant des établissements d'enseignement et de recherche français ou étrangers, des laboratoires publics ou privés. 


\title{
Comparison of multi-pass and regenerative strategies for energetic high-gain amplifiers based on $\mathrm{Yb}^{-\mathrm{CaF}_{2}}$
}

\author{
Frédéric Druon, ${ }^{1, *}$ KéVIN GeneVrier, ${ }^{1,2}$ Patrick GeOrges, ${ }^{1}$ Dimitris N. \\ PAPADOPOULOS ${ }^{2}$ \\ ${ }^{1}$ Université Paris-Saclay, Institut d'Optique Graduate School, CNRS, Laboratoire Charles Fabry, 91127, Palaiseau, France. \\ ${ }^{2}$ LULI, CNRS, ECOLE POLYTECHNIQUE Institut Polytechnique de Paris, CEA, SORBONNE UNIVERSITE, 91128 Palaiseau, France \\ *Corresponding author: frederic.druon@institutoptique.fr
}

Received XX Month XXXX; revised XX Month, XXXX; accepted XX Month XXXX; posted XX Month XXXX (Doc. ID XXXXX); published XX Month XXXX

The Yb-doped materials, due to their high saturation fluence and consequently their low gain, represent a challenging choice for high-energy amplifiers. In this paper, we study two original amplifier designs adapted to a large number of passes capable to operate in the 100 -mJ-energy range at repetition rates up to $100 \mathrm{~Hz}$ using Yb:CaF 2 crystals as active media. Amplification geometries based on double-head active mirror configurations are presented. We confront two alternative strategies suitable for amplification of large beams: regenerative and geometrical multi-pass amplifiers. This work consists in finding the pivot point allowing to discriminate the specific interest of each strategy. We presents compensation methods of the thermal lens adapted to each amplifier configuration with and without cavity- and we demonstrate that despite similar laser heads and pumping conditions, the thermal lens impacts differently the optimal performance for multi-pass or regenerative strategy. We perform amplification up to 66-mJ pulses at $10 \mathrm{~Hz}$ with the regenerative amplifier and $52 \mathrm{~mJ}$ at $100 \mathrm{~Hz}$ with the multipass amplifier. (C) 2020 0ptical Society of America

http://dx.doi.org/10.1364/OL.99.099999

Yb-doped crystals have been demonstrated as interesting materials for diode-pumped energetic systems [1-2]. Indeed, they allow the development of efficient and high-power, high-energy lasers. However, due to their generally low gain and high saturation fluence, several issues remain in terms of energy extraction in such amplifiers. Often a very high number of passes is required making the balance between gain and losses very critical. Furthermore, high-energy amplifiers require large beam diameters -to avoid damage- which introduces an additional sensitivity to spatial distortions of the beam. Critical choices have to be made therefore to obtain optimal operation of energetic amplifiers with Yb-doped crystals, among which the choice of the strategy between regenerative amplifier and geometric multi-pass amplifier. Actually, due to the combination of high number of passes and loss sensitivity, none of the strategies clearly overrides the other. The high number of passes and the cavity mode cleaning seem to work in favor of the regenerative amplifier in terms of simplicity; however, the sensitivity to losses and the mode-matching criticality favor the choice of the geometric multipass. The choice between the two strategies does not appear as obvious in the literature, especially for the case of high-energy Ybdoped-material amplifiers[3-13]. In order to go a step beyond the simple general tendencies and assumptions, we perform a comparative evaluation to demonstrate what are the main issues for each architecture and when one prevails over the other. This work has been performed with the $\mathrm{Yb}: \mathrm{CaF}_{2}$ crystal as active medium which presents great interest for energetic amplifiers due in particular to its long storage lifetime[14-16]. Its low gain however, makes it relatively critical to use in high-energy amplifiers especially if a total high gain is required. Furthermore, the requirement of large beam diameter -to avoid damage- leads to extended amplifier configurations, very sensitive to thermo-optical distortions. In this paper, we developed original architectures using two laser heads in active-mirror configuration pumped with a unique laser diode; thermal-lens geometrical compensations are also demonstrated for both strategies: regenerative and multi-pass amplifiers. The limitations for high power systems due to mode matching will be also analyzed.

The amplifiers are based on two laser heads using 2.2-\%-doped $\mathrm{Yb}: \mathrm{CaF}_{2}$ crystal discs with a diameter of $15 \mathrm{~mm}$ and with a thickness of $2 \mathrm{~mm}$ or $2.8 \mathrm{~mm}$ (optimized versus the amplifier strategy). The crystals are used in active mirror configuration, for both signal and pump, with an AR coating on the front, and a HR coating on the back faces respectively for both pump and signal wavelengths. The crystals are contacted on copper mounts using a soft highly thermally conductive glue in order to reduce the 
mechanical stresses. For the design of the amplifier, the static wavefront distortions of the mounted crystals have been measured using a Fizeau interferometer. The interferograms for both faces are given in Fig. 1a,1b. The static wavefront distortions are principally due to the mechanical stress of the coatings in both faces, presenting a nearly pure quadratic form with radii of curvature on the AR face of $28 \mathrm{~m}$ and $33 \mathrm{~m}$ for the HR one. The unpumped active mirrors can be therefore considered as concave mirrors with a radius of curvature of $35 \mathrm{~m}$.

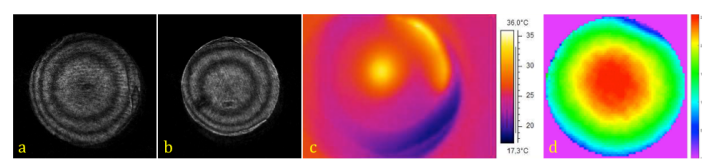

Fig. 1. Interferograms of static distortions observed on the $\mathrm{Yb}: \mathrm{CaF}_{2}$ discs for the AR (a) and HR (b) faces indicating radii of curvature of $28 \mathrm{~m}$ and $33 \mathrm{~m}$ respectively. Temperature profile (c) and thermal lens (d) measurement for $200 \mathrm{~W}$ of pump average power (1-kW, 2-ms, $100 \mathrm{~Hz}$ ).

The pumping system consists in a $600-\mu \mathrm{m}$-diameter fiber coupled laser diode emitting $1 \mathrm{~kW}$ of peak power at $980 \mathrm{~nm}$. The pump has an angle of incidence of $8^{\circ}$. In nominal operation mode the pump source delivers $2 \mathrm{~ms}$ pulses at $100 \mathrm{~Hz}$ repetition rate, corresponding to $200 \mathrm{~W}$ of average power. For the 2.8-mm thick crystal and with a pump spot size of $2.5-\mathrm{mm}$ diameter, the temperature rises up to $36^{\circ} \mathrm{C}$ (Fig. 1c) with an equivalent thermal lens of $\mathrm{f}_{\text {th } 1}=4.1 \mathrm{~m}$ (Fig. 1d) [17-18]. The corresponding absorbed pump power in the crystal is $86 \mathrm{~W}$. The remaining pump power is not negligible and it is re-imaged in a second similar crystal as shown in Fig. 2 and 5 representing the amplifier setups. The second crystal absorbs $55 \mathrm{~W}$ and experiences a thermal lens of $\mathrm{f}_{\text {th2 }}=6.4 \mathrm{~m}$. The double-head amplifier design will take into account this slightly unbalanced thermal lenses. The amplifiers are designed to support $100-\mathrm{mJ}$ amplification. The injection consists in a 5-ns square-shape pulses at $1030 \mathrm{~nm}$-produced by a programmable pulse generator (from Photline) with 125-ps time resolution - subsequently amplified in a Yb:KYW regenerative amplifier (from Amplitude Laser) to reach $220 \mu$ J.

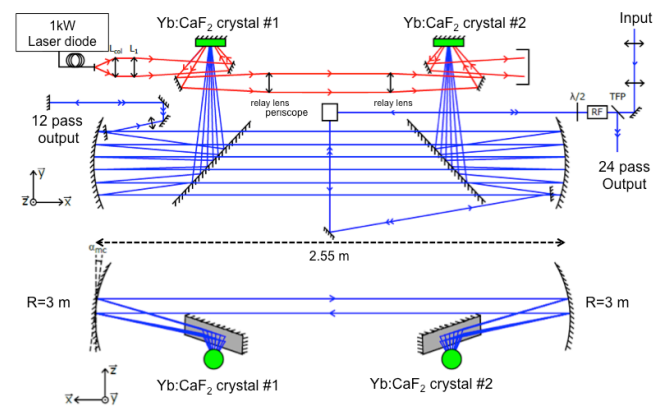

Fig. 2. Setup of a 3D-double active-mirror multipass amplifier. Top and side views of the multipass cell are represented.

The first strategy consists in amplifying in a multi-pass amplifier. The setup is described in Fig. 2. The amplifier is based on a quasi-4$\mathrm{f}$ image-relay line composed of two 3-m ROC mirrors (4-inch in diameter), where each one of the active mirrors is precisely positioned on the image planes. In order to compensate the thermal lens, the distance D between the two 3-m ROC mirrors has to be reduced to $2.55 \mathrm{~m}$ according the equation: $\mathrm{D}=\mathrm{R}-\mathrm{R}^{2}\left(1 / \mathrm{f}_{\text {th } 1}+1 / \mathrm{f}_{\text {th } 2}\right) / 8$. As shown in fig. $3 \mathrm{~b}$, the round-trip beam size is then preserved all along the propagation. Indeed, without compensation (uncompensated perfect 4-f-line, Fig. 3a) the beam sizes on the crystals are constant for all the passes but they vary drastically on the other mirrors. In this quasi-relay-imaging system, it is important to note that none of the mirrors experiences less than 2-mm diameter beams and the beam is larger than 2.5$\mathrm{mm}$ on the $\mathrm{CaF}_{2}$ crystals to assure fluences well below the damage threshold of the amplifiers optics $\left(<10 \mathrm{~J} / \mathrm{cm}^{2}\right)$.

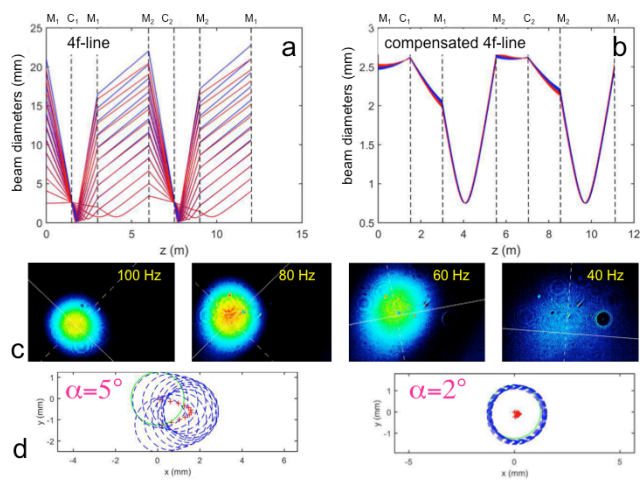

Fig. 3. Thermal lens compensation for the 3D-double active-mirror multi-pass amplifier. The crystals are in C1 and C2 plans. Beam evolution for a) uncompensated 4-f line, b) compensated quasi-4-f line. c) Experimental beam evolution after 8 round-trips for different repetition rates, the nominal rate being $100 \mathrm{~Hz}$. d) Influence of the offplan angle $(\alpha)$ on the overlap of the multiple passes on the crystals for $\alpha=5^{\circ}$ and $\alpha=2^{\circ}$ (beam print: blue discs, beam barycenter: red crosses).

In counterpart, the quasi-imaging implies, first, a nominal pump power and the impossibility of changing the repetition rate without complex modifications of the multi-pass cavity distances (Fig. 3c). Indeed, the change of repetition rate does reveal a no real improvement in extracted energy and the optimization process could lead to damage of the crystals. Second, a particular care is required to assure the best overlap of the different passes in the pumped volume of the active media. Indeed, the amplifier is designed in 3D by slightly tilting off-plane the concave mirrors. In this not perfect quasi-relay imaging configuration, the influence of this angle $\alpha$ (defined in Fig. 2 ) is not anodyne as represented in Fig. $3 \mathrm{~d}$. The angle has to be chosen to avoid a large spread of the beam on the crystal in order to preserve a good overlap between signal and pump beams. Assuming this overlap for the different passes, we were able to perform numerical simulations (based on a 2D Frantz-Nodvik model) to evaluate the laser gain, considering a 2.5$\mathrm{mm}$ diameter pumping spot and with the signal beam estimated by the beam propagation (Fig. 3). The calculated small signal gain per roundtrip (one double pass for each crystal) is then 1.357 and the total stored energy $655 \mathrm{~mJ}$ (for both crystals).

In order to experimentally validate this small signal gain, we measured the output energy versus the number of passes with 56 $\mu \mathrm{J}$ of injected energy. The fitting curve (Fig. 4a) indicates a gain per round trip of 1.306 . The global losses per round trip are then evaluated at $5 \%$ which is fully coherent with the losses estimated 
per mirror $(0.4 \%)$ and per AR coating $(0.3 \%)$. The maximum energy (for an injected energy of $0.22 \mathrm{~mJ}$ ) then reaches $5 \mathrm{~mJ}$. This regime is far from the saturation regime and shows a linear evolution (Fig. 4b) corresponding to a typical unsaturated regime. The total gain is then 24.6 for 12 round-trips.

To increase further the energy, the signal beam is recycled backward in the amplifier and extracted using an optical isolator. 24 round-trips are then obtained slightly re-optimizing the lengths to maximize the efficiency. The backward cycle does not follow the same amplification curve than the one described by the 12 first passes -as shown in Fig. 4c-. Indeed, during backward amplification, the beam profile is different. Even if the divergence is theoretically compensable by the recycling imaging system, in practice we have seen that there was no way to obtain a perfect reinjected beam, due, according to us, to the higher order thermal aberrations that lead to a slightly different optimal beam dimension. The optimal divergence at the output leads to a beam $1.5 \mathrm{x}$ larger than the one measured after the 12 first round-trips (insets Fig. 4b and 4c). This indicates that the beam on the crystals is slightly reduced down to $1.8 \mathrm{~mm}$ for all the 12 passes in the backward direction. This tends to exacerbate the saturation effect as shown with the numerical simulations in fig. $4 \mathrm{~d}$ indicating a drop of the theoretically expected energy from $80 \mathrm{~mJ}$ down to 67 $\mathrm{mJ}$. The aggravated divergence of the output beam also impacts on the losses, in particular in the optical isolator and in the amplifier propagation. In the last simulation, we estimate these extra losses at $1 \%$ per round-trip. With these new parameters, the maximum energy then reaches $54 \mathrm{~mJ}$ (for an injected power of $0.22 \mathrm{~mJ}$ ) instead of $80 \mathrm{~mJ}$ (estimated based on the gain measurement of the 12 first passes). The average gain per round-trip is reduced to 1.26 . The difficulty of the 4-f multipass system, is clearly highlighted here. Indeed, due to a cumulating process of phase distortions, the compensation of the quasi 4-f line cannot be with the same optimum when incrementing the number of passes. Moreover, at high extraction level the risk of damages became an experimental obstacle in the seeking of ideal compensation.
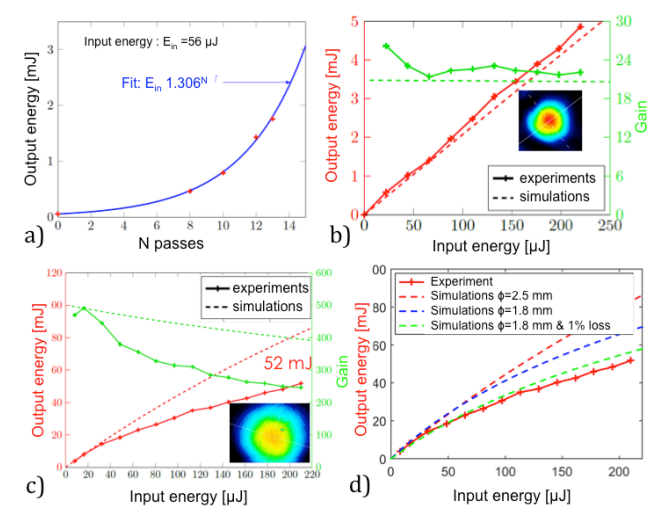

Fig. 4. a) Output energy vs different numbers of passes for $56 \mu \mathrm{J}$ injected energy, b) Multi-pass output energy and gain for 12 roundtrips versus input energy, c) Multi-pass output energy and gain for $2 \times 12$ roundtrips versus injected energy. The inset shows the output beam profiles at maximum energy. d) comparison with the numerical simulations for different beam sizes in the crystals; the red dashed lines present the numerical simulations considering no modification between the forward and backward cycles. The green dashed line presents the numerical simulations taking into account the beam size evolution and associated extra losses (+1\%).

One can then legitimately rise counter-arguments against the multi-pass amplifier concerning, first, the difficulty of increasing the number of passes and, second, in preserving the beam quality all along the amplification process. The alternative strategy of regenerative amplification, where the beam profile is intrinsically defined by a cavity becomes then legitimate. This second strategy has then been tested. The regenerative amplifier cavity is designed to handle high energies (100 $\mathrm{mJ}$ range) with beam diameters around $2 \mathrm{~mm}$ in the $\mathrm{Yb}: \mathrm{CaF}_{2}$ crystals and $3 \mathrm{~mm}$ in the Pockels cell (PC). The design proposed is detailed in Fig. 5. The cavity is symmetric with respect of the PC that is located in a collimated arm. One of the challenges concerns the maintaining of a very large mode for all the optics. This imposes a low mode-discriminating cavity with very long focal length mirrors: 10-m radius-ofcurvature (ROC) in our case. The consequences are the following: an important cavity length and a strong sensitivity to thermal lenses whose dioptric powers quickly become preponderant over the mirror ROC of the cavity. To overcome this last issue and not to disfavor the regenerative geometry, we, first, have to reduce the $\mathrm{Yb}: \mathrm{CaF}_{2}$ thickness crystals down to $2 \mathrm{~mm}$ (to decrease the total absorption to $60 \%$ which is a good compromise between thermal effects and stored energy and, second, we integrate a specific thermal lens compensation scheme for each crystal.

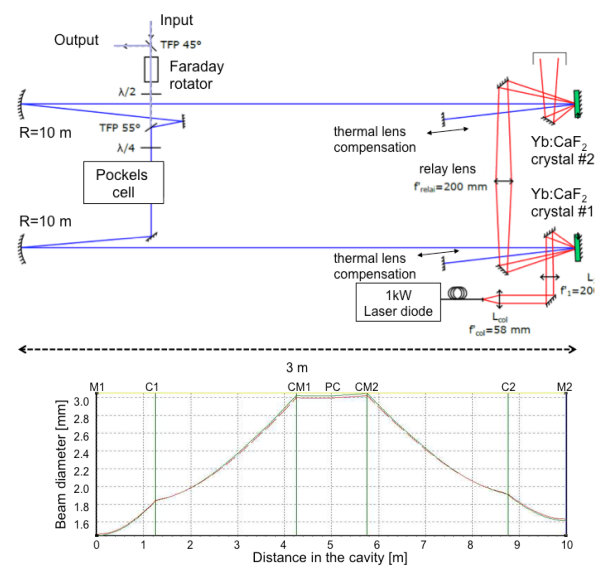

Fig. 5. Regenerative amplifier setup and beam propagation integrating thermal lens compensation ( $8 \mathrm{~m}$ for the crystal $\mathrm{C} 1$ and $12 \mathrm{~m}$ for the crystal C2).

The thermal lens at the nominal average pump power $(200 \mathrm{~W})$ is initially estimated at $\mathrm{fth}_{1}=8 \mathrm{~m}$ for the first crystal and $\mathrm{fth}_{2}=12 \mathrm{~m}$ for the second one. These lenses can be compensated positioning the end mirrors around 1-m away from the crystals, as shown in fig. 5 , representing the beam propagation in the cavity at full pump power. In these conditions, the cavity length is about $11 \mathrm{~m}$ (with a round trip time of $67 \mathrm{~ns}$ ). The losses of the cavity are measured by injecting a pulse in the amplifier at null pump power (Fig. 6a). The time decay of the pulse in the cavity indicates $21 \%$ losses per roundtrip, with the major part (13\%) originated from the "unpumped" crystal laser absorption. The passive losses of the cavity are then estimated $\sim 8 \%$ per round trip. This can be considered as low losses taking into account the large number of interfaces: BBO- 
Pockels-cell (4\% losses), thin film polarizer, quarter-wave-plate and 6 mirrors (10 reflections). The first test of the regenerative amplifier is done at low repetition rate. At $10 \mathrm{~Hz}$, it is possible to extract $66 \mathrm{~mJ}$ after 30 round-trips in the cavity allowing to access to the maximal extraction. The beam profile is imposed by the cavity and corresponds to a TEM 00 mode. In this point of view the regenerative amplifier strategy outperforms the multipass strategy. However, when increasing the repetition rate - keeping the optimal compensation of the thermal lens by re-adjusting the end-mirror lengths at each operation point-, the energy drops, as shown in Fig. 6b, and reaches $21 \mathrm{~mJ}$ at $100 \mathrm{~Hz}$.

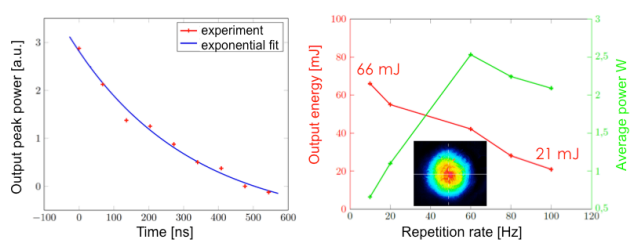

Fig. 6. a) Losses measurement of the regenerative cavity. b) Output energy versus repetition rate for the regenerative cavity (beam profile of the amplified pulses).

In order, to understand this strong decrease, we measured the beam size evolution (Fig. 7) in the cavity for the case of low and high repetition rate, (both being each time optimized regarding the thermal lens compensation). It appears clearly that by increasing the number of round-trips, the cavity plays correctly its role of spatial filtering, imposing quickly its eigenmode. Even if the thermal lens compensation is correct in both cases with same beam sizes, the shape appears more filtered in the high power case, mainly due to higher order phase distortions. And this enhanced mode filtering is necessarily synonymous of extra losses. The greater is the mismatching, the higher are the losses. This mainly explains the drop of energy observed between $10 \mathrm{~Hz}$ and $100 \mathrm{~Hz}$ from $66 \mathrm{~mJ}$ to $21 \mathrm{~mJ}$ respectively. Other combined effects such thermal dependency of the gain can also play a role.

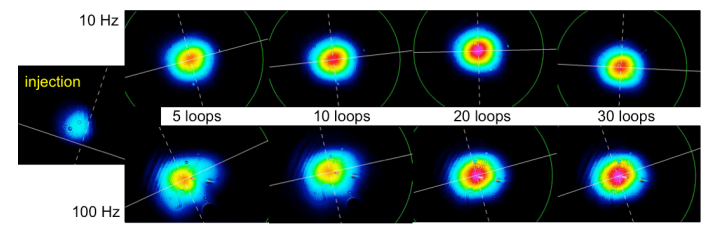

Fig. 7. Evolution of the beam profile of the cavity versus the number of round-trips in the large-mode regenerative amplifier and for low and high repetition rates.

In conclusion, we demonstrated two high-energy amplifier architectures based on 3D-relay imaging multi-pass or regenerative configurations. These demonstrations represent, to our best knowledge, the first comparison between these two oftenconfronted strategies for low gain amplifiers. They allowed to obtained performances at the state of the art with $\mathrm{Yb}_{\mathrm{CaF}} \mathrm{Ca}_{2}$ crystals. Moreover, we proposed a method in order to optimize low-gain energetic amplifiers with high numbers of passes and with thermal issues considering both architectures. The result of this method on multi-head 3D amplifiers with quasi-relay imaging or large mode thermal-lens-compensated regenerative amplifiers can be profitable to other lasers technologies such as Yb:YAG. Considering the best architecture to adopt, we clearly adopt a neutral point of view in order to extract a pivot point allowing to discriminate the specific interest of each strategy for different operating points. At low repetition rate, it appears that the regenerative amplifier prevails: we obtained 66-mJ pulses at the $10 \mathrm{~Hz}$. But, for higher repetition rates, the use of a more complex system using a 3Dmulti-pass geometry is required. This system, with much more issues to be integrated in terms of mode-overlapping, allowed the generation of pulses with an energy of $52 \mathrm{~mJ}$ at $100 \mathrm{~Hz}$. With this relatively wide-ranging work, we hope we will help laser designers in the choice between the two competing architectures that are relay imaging multi-pass and regenerative amplifiers.

Funding. ILE APOLLON (07-CPER 017-01);

Disclosures. The authors declare no conflicts of interest.

\section{References}

1. M. Hornung, S. Keppler, R. Bödefeld, A.Kessler, H. Liebetrau, J. Körner, M. Hellwing, F.Schorcht, O. Jäckel, A. Sävert, J. Polz, A. K. Arunachalam, J. Hein, M. C. Kaluza, Opt. Lett. 38(5), 718-720 (2013)

2. F. Druon, F. Balembois, P. Georges, IEEE Photonics J. 268-273 (2011) 3 J.-P. Negel, A. Voss, M.A. Ahmed, D. Bauer, D. Sutter, A. Killi, T. Graf, Opt. Lett. 38, 5442 (2013)

4 T. Nubbemeyer, M. Kaumanns, M. Ueffing, M. Gorjan, A. Alismail, H. Fattahi, J. Brons, O. Pronin, H. G. Barros, and Z. Major, Opt. Lett. 42(7), 1381-1384 (2017).

5. M. Siebold, M. Hornung, S. Bock, J. Hein, M.C. Kaluza, J. Wemans, R. Uecker, , Appl. Phys. B 89(4), 543-547 (2007)

6. M. Siebold, M. Hornung, R. Boedefeld, S. Podleska, S. Klingebiel, C. Wandt, F. Krausz, S. Karsch, R. Uecker, A. Jochmann Opt. Lett. 33(23), 2770-2772 (2008)

7. T. Balciunas, G.Y. Fan, G. Andriukaitis, A. Pugzlys, A. Baltuska,. Opt. Lett. 37(13), 2547-2549 (2012)

8. E. Kaksis, G. Almasi, J.A. Fülöp, A. Pugzlys, A. Baltuska, G. Andriukaitis, Opt. Exp. 24, 28915 (2016)

9. S. Ricaud, F. Druon, D. N. Papadopoulos, P. Camy, J.-L. Doualan, R. Moncorgé, M. Delaigue, Y. Zaouter, A. Courjaud, P. Georges, E. Mottay, Opt. Lett. 35(14), 2415-2417 (2010)

10. D. N. Papadopoulos, A. Pellegrina, L. P. Ramirez, P. Georges, F. Druon, Opt. Lett. 36(19), 3816-3818 (2011)

11. D.N. Papadopoulos, F. Friebel, A. Pellegrina, M. Hanna, P. Camy, J.L. Doualan, R. Moncorge, P. Georges, F. Druon, J. Select. Topics Quant. Electron., (Vol. 21, Issue: 1) (2015)

12 P. Krötz, C. Wandt, C. Grebing, C. Herkommer, R. Jung, S. Klingebiel, S. Prinz, C. Y. Teisset, K. Michel, T. Metzger, in Advanced Solid State Lasers, (Optical Society of America, 2019)

13 T. Dietz, M. Jenne, D. Bauer, M. Scharun, D. Sutter, A. Killi, Opt. Express 28, 11415-11423 (2020)

14. M. Siebold, S. Bock, U. Schramm, B. Xu, J.L. Doualan, P. Camy, R. Moncorgé, Appl. Phys. B 97(2), 327-338 (2009)

15. R. Moncorgé, P. Camy, J.L. Doualan, A. Braud, J. Margerie, L.P. Ramirez, A. Jullien, F. Druon, S. Ricaud, D.N. Papadopoulos, P. Georges, J. Lumin. 133, 276-281(2013)

16. F. Druon, S. Ricaud, D. N. Papadopoulos, A. Pellegrina, P. Camy, J.L. Doualan, R. Moncorgé, A. Courjaud, E. Mottay, P. Georges, Opt. Mater. Express 1(3), 489-502 (2011)

17. S. Chénais, F. Druon, S Forget, F. Balembois, P. Georges, Prog. Quantum Electron. 30(4), 89-153 (2006)

18. J. Boudeile, J. Didierjean, P. Camy, J.L. Doualan, A. Benayad, V.

Ménard, R. Moncorgé, F. Druon, F. Balembois, P. Georges, Opt. Express 16(14), 10098-10109 (2008) 


\section{Complete References}

1. Marco Hornung, Sebastian Keppler, Ragnar Bodefeld, Alexander Kessler, Hartmut Liebetrau, Jorg Korner, Marco Hellwing, Frank Schorcht, Oliver Jackel, Alexander Savert, Jens Polz, Ajay Kawshik Arunachalam, Joachim Hein, Malte C. Kaluza, Highintensity, high-contrast laser pulses generated from the fully diode-pumped $\mathrm{Yb}$ :glass laser system POLARIS. Opt. Lett. 38(5), 718-720 (2013)

2. F. Druon, F. Balembois, P. Georges, New materials for shortpulse amplifiers. IEEE Photonics J. 3(2), 268-273 (2011)

3. Jan-Philipp Negel, Andreas Voss, Marwan Abdou Ahmed, Dominik Bauer, Dirk Sutter, Alexander Killi, and Thomas Graf, "1.1 kW average output power from a thin-disk multipass amplifier for ultrashort laser pulses," Opt. Lett. 38, 5442-5445 (2013)

4. T. Nubbemeyer, M. Kaumanns, M. Ueffing, M. Gorjan, A. Alismail, H. Fattahi, J. Brons, O. Pronin, H. G. Barros, and Z. Major, "1 kW, $200 \mathrm{~mJ}$ picosecond thin-disk laser system," Opt. Lett. 42(7), 1381-1384 (2017).

5. M. Siebold, M. Hornung, S. Bock, J. Hein, M.C. Kaluza, J. Wemans, R. Uecker, Broad-band regenerative laser amplification in ytterbium-doped calcium fluoride (Yb:CaF2). Appl. Phys. B 89(4), 543-547 (2007)

6. Mathias Siebold, Marco Hornung, Ragnar Boedefeld, Sebastian Podleska, Sandro Klingebiel, Christoph Wandt, Ferenc Krausz, Stefan Karsch, Reinhard Uecker, Axel Jochmann et al., Terawatt diode-pumped Yb:CaF2 laser. Opt. Lett. 33(23), 2770-2772 (2008)

7. T. Balciunas, G.Y. Fan, G. Andriukaitis, A. Pugzlys, A. Baltuska, High-power top-hat pulses from a $\mathrm{Yb}$ master oscillator power amplifier for efficient optical parametric amplifier pumping. Opt. Lett. 37(13), 2547-2549 (2012)

8. E. Kaksis, G. Almási, J. A. Fülöp, A. Pugžlys, A. Baltuška, and G. Andriukaitis, "110-mJ 225-fs cryogenically cooled Yb:CaF2 multipass amplifier," Opt. Express 24, 28915-28922 (2016)

9. Sandrine Ricaud, Fre'de'ric Druon, Dimitris N. Papadopoulos, Patrice Camy, Jean-Louis Doualan, Richard Moncorge, Martin Delaigue, Yoann Zaouter, Antoine Courjaud, Patrick Georges et al., Short-pulse and high-repetition-rate diodepumped $\mathrm{Yb}: \mathrm{CaF} 2$ regenerative amplifier. Opt. Lett. 35(14), 2415-2417 (2010)

10. Dimitrios N. Papadopoulos, Alain Pellegrina, Lourdes Patricia Ramirez, Patrick Georges, Fre'de'ric Druon, Broadband highenergy diode-pumped Yb:KYW multipass amplifier. Opt. Lett. 36(19), 3816-3818 (2011)

11. D.N. Papadopoulos, F. Friebel, A. Pellegrina, M. Hanna, P. Camy, J-L Doualan, R. Moncorge, P. Georges, F. Druon, "High Repetition Rate Yb:CaF2 Multipass Amplifiers Operating in the 100-mJ Range" Invited in Selected Topics in Quantum Electronics, IEEE Journal of (Volume:21 , Issue: 1 ) (2015)

12. P. Krötz, C. Wandt, C. Grebing, C. Herkommer, R. Jung, S. Klingebiel, S. Prinz, C. Y. Teisset, K. Michel, and T. Metzger, "Towards $2 \mathrm{kw}, 20 \mathrm{khz}$ ultrafast thin-disk based regenerative amplifiers," in Advanced Solid State Lasers, (Optical Society of America, 2019)
13. Thomas Dietz, Michael Jenne, Dominik Bauer, Michael Scharun, Dirk Sutter, and Alexander Killi, "Ultrafast thin-disk multi-pass amplifier system providing $1.9 \mathrm{~kW}$ of average output power and pulse energies in the $10 \mathrm{~mJ}$ range at $1 \mathrm{ps}$ of pulse duration for glass-cleaving applications," Opt. Express 28, 11415-11423 (2020)

14. M. Siebold, S. Bock, U. Schramm, B. Xu, J.L. Doualan, P. Camy, R. Moncorgé, Yb:CaF2 - a new old laser crystal. Appl. Phys. B 97(2), 327-338 (2009)

15. R. Moncorge', P. Camy, J.L. Doualan, A. Braud, J. Margerie, L.P. Ramirez, A. Jullien, F. Druon, S. Ricaud, D.N. Papadopoulos et al., Pure and Yb3. doped fluorites (Ca, Sr, $\mathrm{Ba}) \mathrm{F} 2$ : a renewal for the future high intensity laser chains. J. Lumin. 133, 276-281 (2013)

16. F. Druon, Sandrine Ricaud, Dimitris N. Papadopoulos, Alain Pellegrina, Patrice Camy, Jean Louis Doualan, Richard Moncorge, Antoine Courjaud, Eric Mottay, Patrick Georges, On $\mathrm{Yb}: \mathrm{CaF} 2$ and $\mathrm{Yb}: \mathrm{SrF} 2$ : review of spectroscopic and thermal properties and their impact on femtosecond and high power laser performance [invited]. Opt. Mater. Express 1(3), 489-502 (2011)

17. Sebastien Chénais, Frederic Druon, Sebastien Forget, François Balembois, Patrick Georges, On thermal effects in solid-state lasers: the case of ytterbium-doped materials. Prog. Quantum Electron. 30(4), 89-153 (2006)

18. J. Boudeile, J. Didierjean, P. Camy, J.L. Doualan, A. Benayad, V. Menard, R. Moncorge, F. Druon, F. Balembois, P. Georges, Thermal behaviour of ytterbium-doped fluorite crystals under high power pumping. Opt. Express 16(14), 10098-10109 (2008) 